\title{
LASER INDUCED OXIDATION OF HEAVILY DOPED SILICON*
}

E. FOGARASSY**, C.W. WHITE, D.H. LOWNDES, AND J. NARAYAN

Solid State Div., Oak Ridge National Laboratory, Oak Ridge, TN 37831, USA

**Centre de Recherches Nucléaires, Laboratoire Phase, 23, rue du Loess, F-67037 Strasbourg Cedex, FRANCE

\section{ABSTRACT}

$$
\text { CONF-851260--2 }
$$

DE86 006212

We have investigated the incorporation of oxygen into heavily doped silicon during UV excimer laser irradiation. For the case of repetitive laser irradiations in air, we observe that the amount of oxygen incorporated into $\mathrm{Si}$ depends markedly on the dopant. For As and $\mathrm{Sb}$ implanted silicon, there is no anomalous oxygen incorporation. By contrast, increasing amounts of 0 are incorporated into In implanted silicon as a function of number of laser shots. The incorporation of 0 is associated with degradation of the optical and structural properties of the surface, and a deep diffusion of the dopant. This behavior is believed to be partly related to specific chemical reactions between oxygen and indium present in the surface at high concentrations as the result of dopant segregation during solidification.

\section{INTRODUCTION}

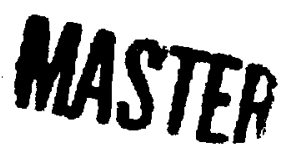

In the past few years, several investigations have been performed to examine the incorporation of oxygen into silicon during laser annealing (in an oxygen or air environment) using continuous wave [1-4] or pulsed lasers [5], working in solid and liquid phase regimes respectively. Recent work performed on virgin crystalline silicon using ultra-violet laser irradiation resulted in a high rate of oxidation of the sample $[6,7]$. The oxide formation was attributed to adsorption of oxygen by the molten silicon when the near surface was melted by the laser treatment. In this study, we have investigated the incorporation of oxygen into heavily doped silicon during repetitive UV laser irradiation in air or in a controlled atmosphere. We observe that the rate of oxygen incorporation depends markedly on the dopant. In addition, 0 incorporation is associated with important modifications in the properties of the doped layer; these include degradation of optical and structural properties of the surface, a reduction in the dopant solubility, and deep diffusion of the dopant.

\section{EXPERIMENTAL CONDITIONS}

Different dopants such as arsenic (100 keV), antimony (150 keV) and indium (125 keV) were implanted into $F Z$ silicon substrates of $\langle 100\rangle$ orientation, to doses in the range $5 \times 10^{15} \mathrm{~cm}^{-2}$ to $5 \times 10^{16} \mathrm{~cm}^{-2}$. Laser annealing was carried out in air using repetitive UV pulses $(1 \mathrm{~Hz}, 35 \mathrm{nsec}$ FWHM), provided by a KrF excimer laser $(\lambda=248 \mathrm{~nm})$. The laser energy density could be varied between 0.5 and $1.3 \mathrm{~J} / \mathrm{cm}^{2}$. The amount of oxygen incorporated and the total and substitutional dopant distribution profiles were determined by Rutherford backscattering and ion channeling measurements performed along the $\langle 110\rangle$ direction, using a $2.5 \mathrm{MeV} 4 \mathrm{He}^{t}$ ion beam (diameter $\approx 1 \mathrm{~mm}$ ). The energy of the backscattered particles was measured by a cooled detector, permitting a depth resolution of about $150 \mathrm{~A}$. The structural quality of selected samples was analyzed by transmission e lectron microscopy. 


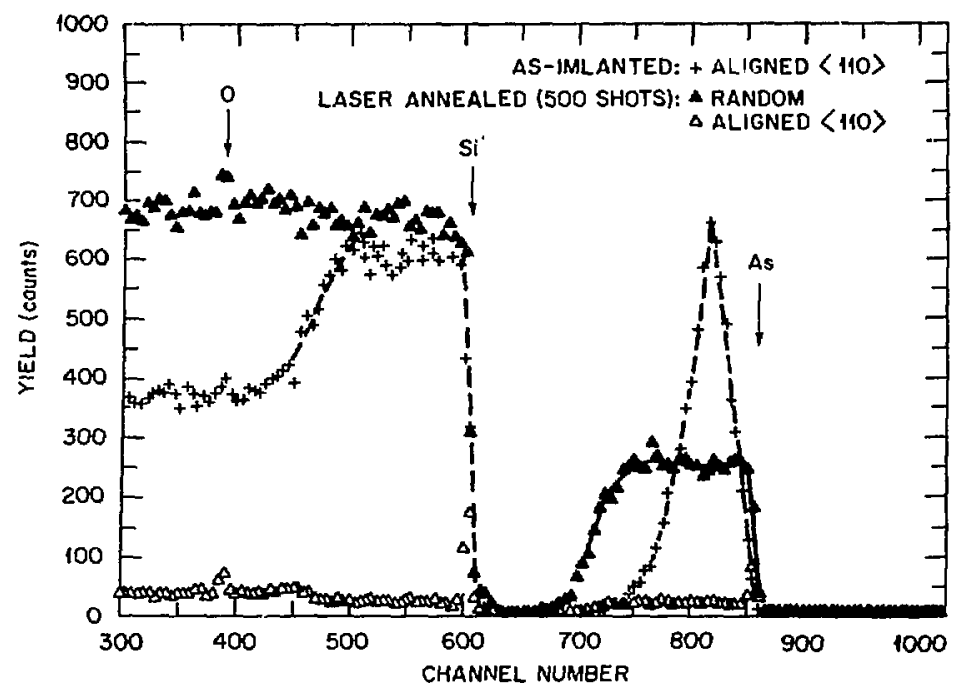

Figure 1: Backscattering spectra for ${ }^{75}$ As $(100 \mathrm{keV}$, $5 \times 10^{16} \mathrm{~cm}^{-2}$ ) implanted into $\langle 100\rangle \mathrm{Si}$ after excimer laser annealing $\left(\mathrm{KrF}, 1.2 \mathrm{~J} / \mathrm{cm}^{2}, 500\right.$ shots).

Channeling spectra (along the $\langle 110\rangle$ direction), reported in Fig. 1 show the recrystallization caused by repetitive laser irradiation (500 shots) of a $2000 \Omega$ thick amorphous Si layer produced by As implantation (100 $\mathrm{keV}, 5 \times 10^{16} \mathrm{~cm}^{-2}$ ). Laser annealing was carried out at $E=1.2 \mathrm{~J} / \mathrm{cm}^{2}$. At this energy density the melt front penetrates both the amorphous and damaged region into the underlying substrate. Under these conditions eptiaxial regrowth occurs as shown by the low value of $x_{\min }(\sim 3.5 \%)$ in the implanted region. The as-implanted As distribution profile is approximately gaussian with a peak near 650A. Laser annealing causes a broadening of As both towards the surface and deeper in depth, which is characteristic of diffusion of As in liquid $S i\left(D_{L}^{A s} \simeq 1.0 \times 10^{-4} \mathrm{~cm}^{2} / \mathrm{sec}\right.$ [8]). After the repetitive laser treatment, we obtain a very uniform arsenic distribution, bounded by a sharp cut-off. This behavior reflects the fact that the effective diffusion distance of As in the liquid silicon after 500 shots is limited by the maximum melt depth $(2500 \mathrm{R})$, a depth which is in reasonable agreement with the predictions of heat flow calculations. The As atoms are a Imost $100 \%$ substitutional in the silicon lattice, with a maximum substitutional concentration of $5 \times 10^{21} \mathrm{~cm}^{-3}$, as determined from channeling experiments; this value, which exceeds the retrograde maximum equilibrium solubility limit $\left(1.5 \times 10^{21} \mathrm{~cm}^{-3}\right.$ at $T=1200^{\circ} \mathrm{C}$ [9]) does not depend on the number of laser shots (between 1 and 500 shots). In this case, oxygen incorporation is limited (as shown in RBS spectra of Fig. 1) to the formation of a thin surface oxide layer not exceeding 50-100 thick. This is in good agreement with the thickness deduced from ellipsometry measurements. This thickness is comparable to that found on pulsed laser treated virgin $\mathrm{Si}\left(\simeq 60 \mathrm{~A}\right.$ of $\left.\mathrm{SiO}_{2}\right)$ after $500 \mathrm{KrF}$ laser shots.

Simi lar experiments have been performed on a $2000 \mathrm{~A}$ thick amorphous Si layer produced by $\mathrm{Sb}$ implantation (150 keV, $5 \times 10^{16} \mathrm{~cm}^{-2}$ ). In this case, multipulse laser annealing (500 shots) was carried out at $E=1.0 \mathrm{~J} / \mathrm{cm}^{2}$. As shown in Fig. 2, epitaxial recrystallization occurs. In contrast to the results for As, the channeling yield stays high in the near surface region due to nonsubstitutional Sb atoms which are accumulated in the walls of a well defined cell structure which results from lateral segregation during 


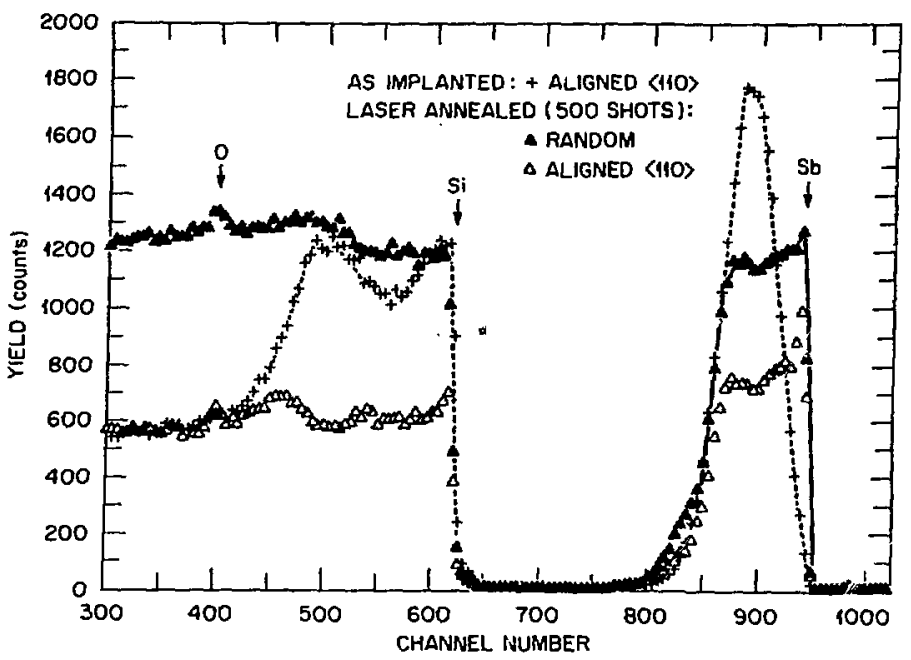

Figure 2: Backscattering spectra for ${ }^{122} \mathrm{Sb}(150$ $\mathrm{keV}, 5 \times 10^{16} \mathrm{~cm}^{-2}$ ) implanted into $\langle 100\rangle$ Si after excimer laser annealing $\left(\mathrm{KrF}, 1 \mathrm{~J} / \mathrm{cm}^{2}\right.$, 500 shots).

The formation of a cell structure (which is observed by transmission e lectron microscopy) results from interfacial instability which develops during regrowth of the molten region and limits the maximum substitutional concentration of $\mathrm{Sb}$ to a value of $2 \times 10^{21} \mathrm{~cm}^{-3}$ (the equilibrium solubility limit is $6 \times 10^{19} \mathrm{~cm}^{-3}$ at $\mathrm{T}=1200^{\circ} \mathrm{C}$ [9]). The distribution of Sb after 500 shots does not differ significantly from the distribution obtained after 1 pulse and is limited in depth by the thickness of the molten region ( $\simeq 2100 \AA)$. The amount of oxygen incorporated is limited (after 500 shots) to a value corresponding to a surface oxide layer which does not exceed $100 \AA$ in thickness.

By contrast, a. Targe amount of oxygen is incorporated into In implanted (125 kev, $\left.1.5 \times 10^{16} \mathrm{~cm}^{-2}\right)$ silicon after multiple pulse laser irradiation as shown on channeling spectra obtained after $i$ (Fig. 3) and 500 shots (Fig. 4). After 500 shots the amount of 0 incorporated into In doped $\mathrm{Si}$ is more than one order of magnitude higher (up to $5 \times 10^{17} / \mathrm{cm}^{2}$ ) compared to $\mathrm{As}$ and $\mathrm{Sb}$ doped samples $\left(\simeq 3 \times 10^{16} \mathrm{O} / \mathrm{cm}^{2}\right)$. The compound formed is a complex mixture of silicon, oxygen, and indium. The proportion of In in the near surface does not exceed $1 \%$. The atomic composition of this oxide layer has been estimated from the ratio of $\mathrm{Si}$ and 0 signal heighis. The top surface consists of a thin stochiometric' $\mathrm{SiO}_{2}$ layer of about $200 \mathrm{~A}$ thickness, covering a non-stochiometric $\mathrm{SiO}_{\mathrm{x}}(\mathrm{x}<2)$ compound. Due to the variation: in composition with depth, we can obtain only a rough estimate of its thickness, which is of the order of 4000-5000A. TEM experiments revealed a very high level of structural damage in the surface region of this oxidized layer.

Several important modifications of the irradiated Si surface are associated with oxygen incorporation. There is a noticeable degradation of surface optical properties. A dull surface develops which is believed to be induced by an increase of surface roughness. In addition, there is a considerable modification of the distribution profile of In following repetitive laser irradiation. After 1 shot the In profile is limited to a depth of $\sim 1000 \AA$ as shown in Fig. 3. After 500 shots In is clearly measured to depths exceeding $5000 \AA$, suggesting that melting occurred at least to this depth (Fig. 4). This result means that there is a strong modification of optical and thermodynamic properties of the surface oxidized layer as compared to pure silicon. Finally, we measure a substitutional In concentration of $3 \times 10^{20} \mathrm{~cm}^{-3}$ after one shot (compared to the equilibrium solubility limit of $\left.\sim 8 \times 10^{17} / \mathrm{cm}^{3}[9]\right)$. The substitutional In concentration is limited by the formation of a cellular structure in the 
surface region. By contrast, af'cer 500 shots the cell structure disappears, as confirmed by TEM, and channeling experiments show no preferred lattice site for In atoms in the oxidized layer.
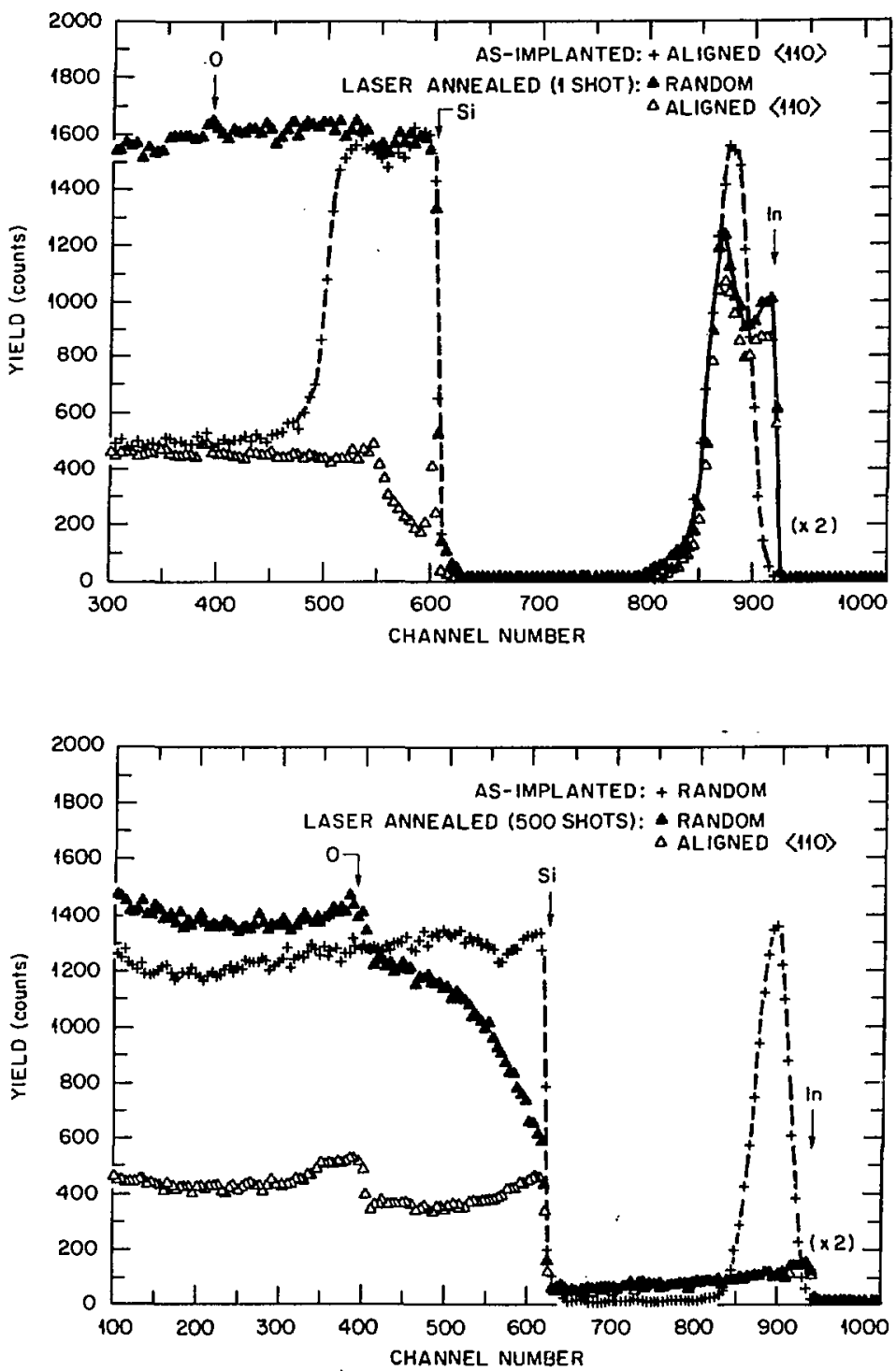

Figure 3: Backscattering spectra for 115 In (125 $\mathrm{keV}, 1.5 \times 10^{16} \mathrm{~cm}^{-2}$ ) implanted into $\langle 100\rangle \mathrm{Si}$ after excimer laser annealing $\left(\mathrm{KrF}, 1 \mathrm{~J} / \mathrm{cm}^{2}\right.$, 1 shot).
Figure 4: Backscattering spectra for 115 In (125 $\mathrm{keV}, 1.5 \times 10^{16} \mathrm{~cm}^{-2}$ ) implanted into $\langle 100\rangle \mathrm{Si}$ after excimer laser annealing $\left(\mathrm{KrF}, 1 \mathrm{~J} / \mathrm{cm}^{2}\right.$, 500 shots).

\section{DISCUSSION}

During irradiation of In implanted (125 keV, $\left.1.5 \times 1016 \mathrm{~cm}^{-2}\right) \mathrm{Si}$ in an argon atmosphere, we do not observe significant oxygen incorporation. This result indicates clearly that surface oxidation is mainly due to adsorption of oxygen from the atmosphere into silicon during the time the surface is molten. During regrowth of the molten layer, the adsorbed oxygen molecules can be trapped into the solid due to the very high regrowth velocity ( $V \cong$ $5-6 \mathrm{~m} / \mathrm{sec}$ as deduced from heat flow calculations [11]). However, oxygen trapping is observed to be strongly dependent on the nature of the dopant, since substantial incorporation is only observed with indium. The substitutional solubility of In in laser annealed $S i$ is significantly lower than for $\mathrm{As}$ and $\mathrm{Sb}$. Moreover, significant differences have been found between interfacial segregation coefficients for these elements during rapid solidification of silicon: $K_{A s} \simeq 1, K_{S b} \propto 0.8$, and $K_{I n} \simeq 0.2$ for regrowth velocities near $5 \mathrm{~m} / \mathrm{sec}[10,12]$. 


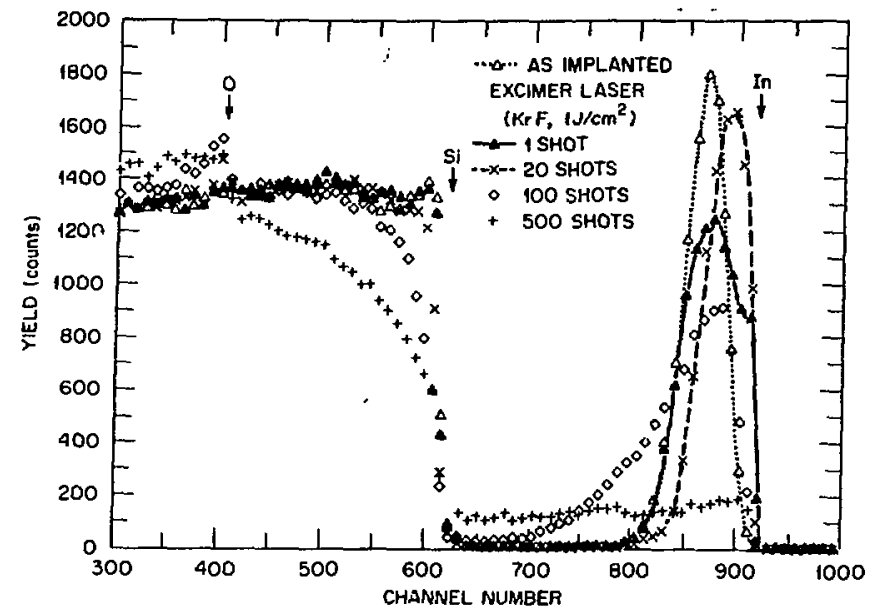

Figure 5: Backscattering spectra for 115 In (125 keV, $1.5 \times 10^{16} \mathrm{~cm}^{-2}$ ) implanted into $\langle 100\rangle \mathrm{Si}$ after excimer laser annealing as a function of the number of laser shots.

Random spectra plotted in Fig. 5 which show the evolution of the In distribution profiles as a function of the number of laser shots, suggest a possible relation between the segregation coefficient and 0 incorporation. Before diffusing deepiy into laser treated Si layer, In atoms segregate strongly towards the surface during the first 20 laser shots. This effect is due to the value of segregation coefficient of In which is significantly lower than 1 during solidification. It is possible that a chemical reaction occurs between oxygen (in air) and indium located at high concentrations in the surface or in cell walls. (We note that the large amount of In atoms accumulated by segregation into the walls of cellular structure following the first laser pulse cannot be responsible alone for the mechanism of 0 incorporation since cells are formed in the Sb implanted case but no anomalous 0 incorporation is observed.) After 20 laser shots only the surface of sample is oxidized as confirmed by the presence of a small peak of oxygen $\left(\approx 5 \times 10^{16} \mathrm{~cm}^{-2}\right)$. Upon increasing the number of laser pulses, we observe a sharp increase of 0 incorporated $\left(\approx 5 \times 10^{17} \mathrm{~cm}^{-2}\right.$ after 500 shots) into the irradiated layer, resulting in a large modification of $S i$ random spectrum between 20 and 500 shots. Deep 0 incorporation is closely related to the extent of the indium distribution profile which diffuses deeper and deeper into the treated layer as a function of the number of shots. A large amount of incorporated 0 is also found following muitipulse laser treatment of bismuth implanted Si. Bi also has an interfacial segregation coefficient which is significantly lower than $1(\simeq 0.3$ for $V \simeq 5$ $\mathrm{m} / \mathrm{sec}$ [12]). However, further experiments are needed to determine the exact nature of the chemical reactions responsible for oxygen incorporation into In and $\mathrm{Bi}$ doped $\mathrm{Si}$. It is clear, however, that the photon wavelength is not important for the mechanism of oxygen incorporation. We have observed similar results using multiple pulse Ruby laser irradiation $(\lambda=$ $0.694 \mathrm{~nm}$ ) of silicon crystals implanted to high doses by In and $\mathrm{Bi}$.

\section{CONCLUSION}

We have demonstrated that incorporation of oxygen into heavily doped silicon during multiple pulse laser irradiation is closely related to the nature of dopant. No anomalous oxygen incorporation is observed for the case of $\mathrm{As}$ and $\mathrm{Sb}$ implanted silicon. By contrast, massive oxygen 
incorporation is observed into the near surface of In and Bi implanted silicon during repetitive laser irradiations. This behavior which may be related to surface segregation phenomena during laser annealing, is associated with degradation of the optical and structural properties of the surface and deep diffusion of the dopant.

\section{REFERENCES}

1) J.F. Gibbons, Jpn J. App 1. Phys. Supp 1. 19, 121 (1980).

2) I.W. Boyd and J.I.B. Wilson, Thin Solid Film, 83, L173 (1981).

3) I.W. Boyd and J.I.B. Wi lson, App 1. Phys. Lett. 41, (2), 162 (1982).

4) S.A. Schafer and S.A. Lyon, J. Vac. Sci. Technol., 19, 494 (1981).

5) K. Hoh, H. Koyama, K. Uda, and Y. Miura, Jpn J. Appl. Phys. 19, n², L375 (1980).

6) Y.S. Liu, S.W. Chiang, and F. Bacon, App 1. Phys. Lett. 38 (12) 1005 (1981).

7) T.E. Or lowski and H. Richter, App 1. Phys. Lett. 45 (3), 241 (1984).

8) P. Baeri, S.U. Campisano, G. Foti, and E. Rimini, Appl. Phys. Lett. $\underline{33}$ (2), 137 (1978).

9) F. Trumbore, Bell Syst. Techn. J. 39, 205 (1960).

10) C.W. White, Laser and Electron Beam Interactions with Solids, edited by B.R. Appletoin and G.K. Celler (North Holland, 1982) P. 109.

11) M. Aziz (private communication).

12) J.M. Poate, Laser and Electron Beam Interactions with Solids, edited by B.R. Appleton and G.K. Celler (North Holland, 1982) p. 121 . 


\section{DISCLAIMER}

This report was prepared as an account of work sponsored by an agency of the United States Government. Neither the United States Government nor any agency thereof, nor any of their employees, makes any warranty, express or implied, or assumes any legal liability or responsibility for the accuracy, completeness, or usefulness of any information, apparatus, product, or process disclosed, or represents that its use would not infringe privately owned rights. Reference herein to any specific commercial product, process, or service by trade name, trademark, manufacturer, or otherwise does not necessarily constitute or inply its endorsement, recommendation, or favoring by the United States Government or any agency thereof. The views and opinions of authors expressed herein do not necessarily state or reflect those of the United States Government or any agency thereof. 